
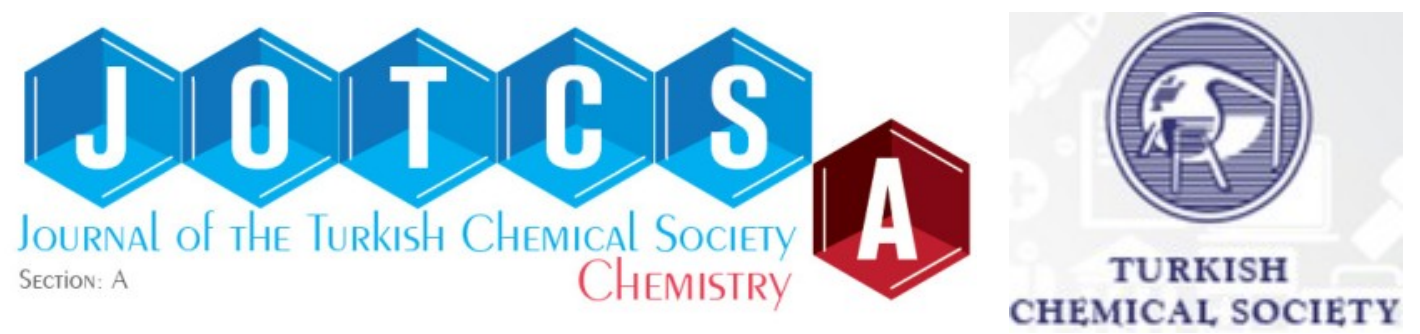

\title{
Swelling, Thermal and Mechanical Characterizations of High-Density Polyethylene/ Recycled Biochar Composites
}

\author{
Sameer A. Awad* \\ Department of Chemistry, University of Anbar, Ministry of Higher Educations and Scientific \\ Resaerch, Anbar, Ramadi 31001, Iraq.
}

\begin{abstract}
The application of recycled natural materials waste as biochar fillers in polymer composites can be observed as a sustainable approach. This article aims to study recycled biochar (R-BCH) improvements on the high-density polyethylene (HDPE) matrix properties. A series of composites was developed with a different loading varying from 0 to $10 \mathrm{wt} \%$ of $\mathrm{R}-\mathrm{BCH}$, using a twin-screw extruder followed by compression molding. The results showed that the addition of $3-10 \%$ of R-BCH in pure HDPE led to an increase in the tensile strength, modulus of elasticity, and a decrease of elongation at break. Furthermore, the differential scanning calorimetry analysis (DSC) results showed that incorporating R$\mathrm{BCH}$ into pure HDPE improved thermal properties because interfaces between R-BCH and pure HDPE caused decreased brittle behavior and enhanced the high crosslinking of pure HDPE.
\end{abstract}

Keywords: HDPE, Recycled Biochar, Tensile Strength, Thermal Properties.

Submitted: August 19, 2021. Accepted: October 03, 2021.

Cite this: Awad SA. Swelling, Thermal and Mechanical Characterizations of High-Density Polyethylene/ Recycled Biochar Composites. JOTCSA. 2011;8(4):1137-44.

DOI: https://doi.org/10.18596/jotcsa.984583.

*Corresponding author. E-mail: sameer.msc1981@gmail.com.

\section{INTRODUCTION}

A composite involves combining two or more materials and that are blended in each other without a solubilizing material. At least one type of natural filler is incorporated in the dispersed phase in the polymeric material to form a composite. The performance of natural filler in composite materials can be enhanced to achieve appropriate materials regarding durability, thus being more economical than synthetic fillers composites. In addition, these natural fillers provide composites' stiffness and strength and enhance superior chemical and mechanical properties (1-4). High-density polyethylene, medium density polyethylene, lowdensity polyethylene polymers are commonly utilized to produce flexible films and laminates for bags, rigid containers, pipe extrusion, and injection molding of various objects (5). The advantages of
HDPE are characterized by high shrinkage, simple molding, and excellent melt strength (6-11). Biochar can be considered neutral carbon or a negative material that may play an essential role in industrial and construction applications. Biochar is the solid product found from biomass pyrolyses such as wood, agricultural wastes, and municipal wastes. It has consisted of stacked graphene sheets inside crystallites of turbostratic carbon with an amorphous compound (12). Through the thermal decomposition of biomass, biocarbon is a porous solid obtained. It is chemically stable under ambient conditions. The properties of biochar are based principally on the raw material and the pyrolysis temperature utilized in the production procedure. The thermal stability of the biochar obtained from the high pyrolysis temperature typically exceeds $350{ }^{\circ} \mathrm{C}$. Besides, it can have functional groups on its surfaces, facilitating its 
connection with the polymer matrix (13). In recent decades, natural fillers reinforced polymer composites companies and research institutions made no effort to modify alternative bio natural fillers based on the raw material limitation. However, in recent years, there is a scope for the biochar's effective application in thermoplastic composites as a result of its porous structure, large surface area, high carbon loading, which could facilitate the physical bonding with the polymer matrix (14). For example, the impact strength of the polyester reinforced $2.5 \% \mathrm{w} / \mathrm{w}$ of biochar increased by $77.50 \%$, while the constant dielectric rise by $7 \%$ compared with the virgin polyester (15). Another study showed that the electrical conductivity of polyvinyl alcohol (PVA) reinforced with 2 and $10 \% \mathrm{w} / \mathrm{w}$ of biochar exhibited values similar to carbon nanotube and graphene-filled PVA composites. On the other hand, the thermal stability, tensile, and storage moduli for PVA/biochar composites were enhanced with the addition of $\mathrm{BC}(16)$.

Previous studies exhibited that utilizing crop residues or natural wastes such as rice straw, sugar cane, flax, hemp, jute, wood chips, or tea residues to replace wood fibers enhanced notably mechanical and thermal properties of wood-plastic composites (WPCs) (17-19). For example, Wu et al. (20) prepared cotton stalk bark (CSB) reinforced polypropylene (PP), and their mechanical, thermal, and morphology properties were investigated. They observed that the flexural properties and tensile modulus of CSB reinforced PP composites were improved with the increasing loading of CSB. In contrast, the tensile strengths showed a negative correlation with the loading of CSB, which achieved $32.9 \mathrm{MPa}$ when the CSB incorporated was $30 \%$. Another study by Cholake et al. (21) investigated the waste macadamia sell impact on improving the mechanical characterizations of WPC panel. It was displayed that incorporating macadamia shell increased the comprehensive modulus $548 \mathrm{MPa}$ for $75 \%$ compared to the PP matrix.

This paper applied the extrusion fabrication method to prepare bio composites HDPE with $(\mathrm{RBCH})$ obtained by recycled wood chips pyrolysis. The thermal characterizations of $\mathrm{RBCH} / \mathrm{HDPE}$ composites were studied to investigate the crystallization performance. In addition, the mechanical properties of RBCH/HDPE composites were presented and discussed to provide a theoretical basis for the application. In this regard, this study attempts to utilize local resources of wood chips converted to $\mathrm{R}-\mathrm{BCH}$ to reinforce thermoplastic polymers. The $\mathrm{R}-\mathrm{BCH}$ could have a promising future as a new reinforcement in polymer composites as a result of their low cost, low density, environmental friendliness, and great mechanical characterizations.

\section{MATERIALS AND METHODS}

\section{Materials}

$\mathrm{R}-\mathrm{BCH}$ was collected from waste wood chips, cleaned, and dried. HDPE matrix with a density of $0.955 \mathrm{~g} / \mathrm{mL}$ was used as a matrix and provided by Indian Chemical and Petrochemical Manufacture (CPMA).

\section{Preparation of $\mathbf{R}-\mathbf{B C H}$}

The wood waste was dried and then operated through a chipper that turns it into woodchips (20$40 \mathrm{~mm}$ ). The woodchips were then converted through slow pyrolysis at a temperature range $\left(450-550{ }^{\circ} \mathrm{C}\right)$, and the heating rate range was $0.1-1{ }^{\circ} \mathrm{C} / \mathrm{s}$ into syngas to produce biochar. Figure 1 shows a schematic diagram for $\mathrm{R}-\mathrm{BCH}$ preparation.

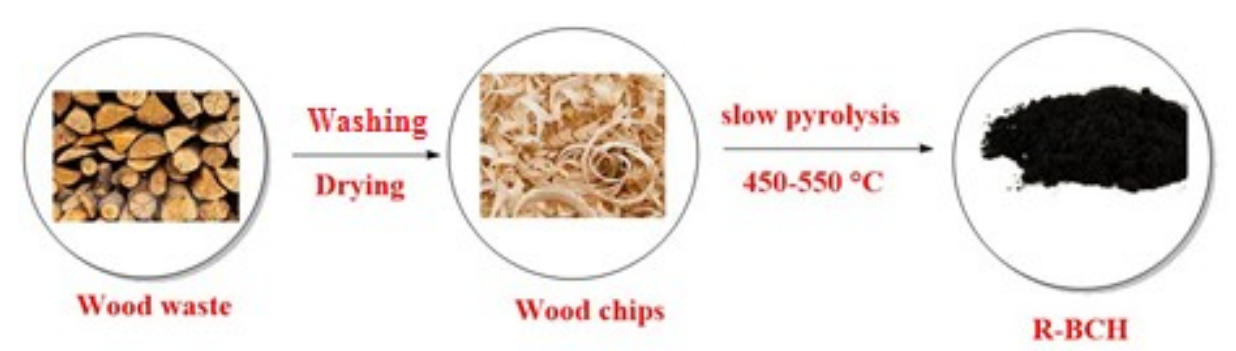

Figure 1: Schematic illustration of the Preparation of $\mathrm{R}-\mathrm{BCH}$.

\section{Fabrication of HDPE Composite}

Initially, the required amounts of HDPE and R-BCH were mixed thoroughly, utilizing a mixer to obtain a homogenous composite (the mixture speed was
$50 \mathrm{rpm}$ at mixing time six minutes). The mixture was then passed through a twin-screw extruder at a temperature of $180^{\circ} \mathrm{C}$ and a screw speed of 10 rpm. Next, the extruded composites were taken 
out from the extruder and compressed in a Carver press at $140{ }^{\circ} \mathrm{C}$ for $30 \mathrm{~min}$ to obtain a sheet $(15 \mathrm{x}$ $15 \mathrm{~cm}^{2}$ ) having a thickness of $1 \mathrm{~mm}$. The amount of $\mathrm{R}-\mathrm{BCH}$ powder added to the matrix varied from $0,3,7$, and $10 w t \%$, respectively. Figure 2 exhibited the proposed scheme for R-BCH/HDPE composite.

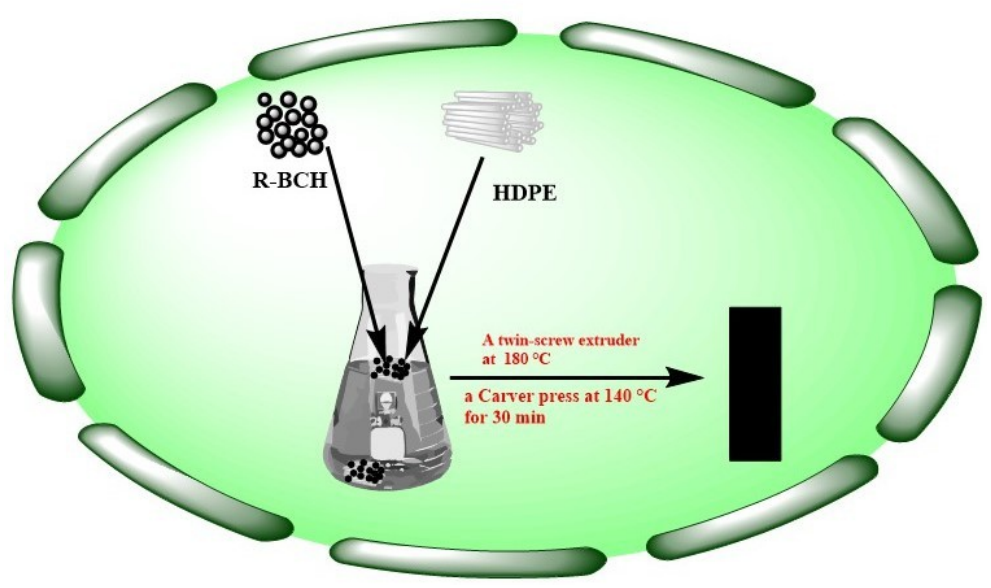

Figure 2: A scheme of HDPE/R-BCH composites preparation.

\section{Swelling Ratio Test}

To measure the swelling ratio (SR), dry HDPE composites $(0.2 \pm 0.5 \mathrm{~g})$ were immersed in $800 \mathrm{~mL}$ of distilled water solutions for $4 \mathrm{~h}$ at room temperature to achieve equilibrium. The swollen product was filtered through a 100 -mesh screen to remove excess moisture and then weighed. Each specimen was significantly tested, and the average value was used. The capacity of water-absorbent was calculated utilizing the following Equation (1):

$$
S R \%=\frac{\left(m_{1}-m_{0}\right)}{m_{0}}
$$

Where $m_{0}$ and $m_{1}$ are the mass of dried and swollen products, respectively.

\section{Differential Scanning Calorimetry}

The blends' characteristics of melting and crystallization were measured utilizing a machine type, a Mettler 820 DSC. The weight of samples was in a range of $5-10 \mathrm{mg}$. The first heating and second heating were done from $25^{\circ} \mathrm{C}$ to $200^{\circ} \mathrm{C}$ at $10{ }^{\circ} \mathrm{C} / \mathrm{min}$ in a nitrogen atmosphere. The DSC thermograms provide details on the melting temperature $\left(T_{m}\right)$, crystallization temperature $(T c)$, melting enthalpy heat $\left(\Delta \mathrm{H}_{\mathrm{m}}\right)$, and crystallization enthalpy heat $(\Delta \mathrm{Hc})$. In addition, the crystallinity degrees $\left(X_{c}\right)$ of the specimens were calculated using Equation 2.

$$
\chi_{c}(\%)=\frac{\Delta H_{m}}{\Delta H_{m}^{0}}
$$

Where $\Delta \mathrm{H}^{\circ} \mathrm{m}$ is the enthalpy heat of fusion of the fully crystalline HDPE, taken as $290 \mathrm{~J} / \mathrm{g}$ (22-24). The $\Delta H_{m}, \Delta H_{c}$, and $X_{c}$ values of HDPE and HDPE composites were normalized and accounted for based on the actual HDPE composites, as listed in Table 1.

\section{Tensile Tests}

Composite samples were tested utilizing an Instron tensile machine model type (Testometric, M50050AT), UK, based on the standard of ASTM D 638. The crosshead speed was about $20 \mathrm{~mm} / \mathrm{min}$. Furthermore, three tests were replicated for each composite sample. 


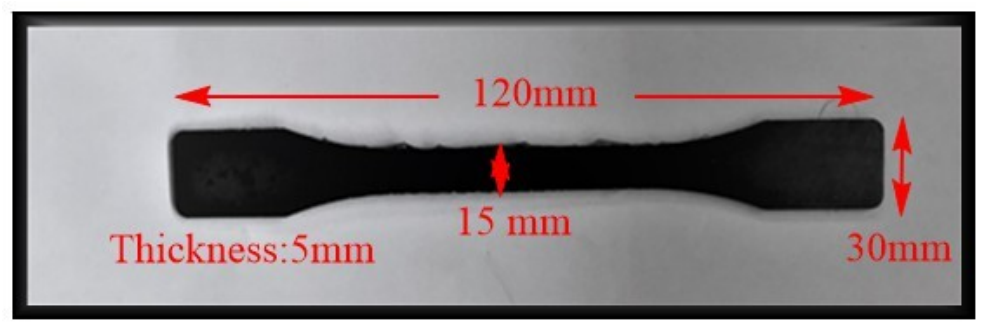

Figure 3: Tensile test simple with dimensions.

\section{RESULTS and DISCUSSIONS}

\section{Swelling Analysis of HDPE Composites}

The swelling ratio measurements against the loading of $\mathrm{R}-\mathrm{BCH}$ composites are illustrated in Figure 4. The introduction of $\mathrm{R}-\mathrm{BCH}$ into $\mathrm{HDPE}$ composites has shown a significant effect on the extrudate swelling ratio. It can be seen from Figure 1 that the swelling ratio of $\mathrm{HDPE} / \mathrm{R}-\mathrm{BCH}$ composites decreased with an increase in the $\mathrm{R}$ $\mathrm{BCH}$ loading. The swelling ratio of $10 \% \mathrm{R}-\mathrm{BCH} /$ HDPE composite was reduced by $64 \%$, while the incorporation of $3 \%$ and $7 \% \mathrm{R}-\mathrm{BCH}$ in $\mathrm{HDPE}$ composites was decreased by $44 \%$ and $50 \%$, respectively. The hypothesis produced concerns the ability of $\mathrm{R}-\mathrm{BCH}$ in permitting further interactions of polymer molecules. An ease in the interaction of the molecules enhances the entanglement level and elastic property of HDPE melt, therefore affecting the deformation rate (in this case, referring to the extrudate swelling). Incorporating the highest loading ( $10 \% \mathrm{R}-\mathrm{BCH})$ in the HDPE matrix showed a sharp decrease compared to other loadings of $\mathrm{R}-\mathrm{BCH}$ ( $3 \%$ and $7 \%)$.

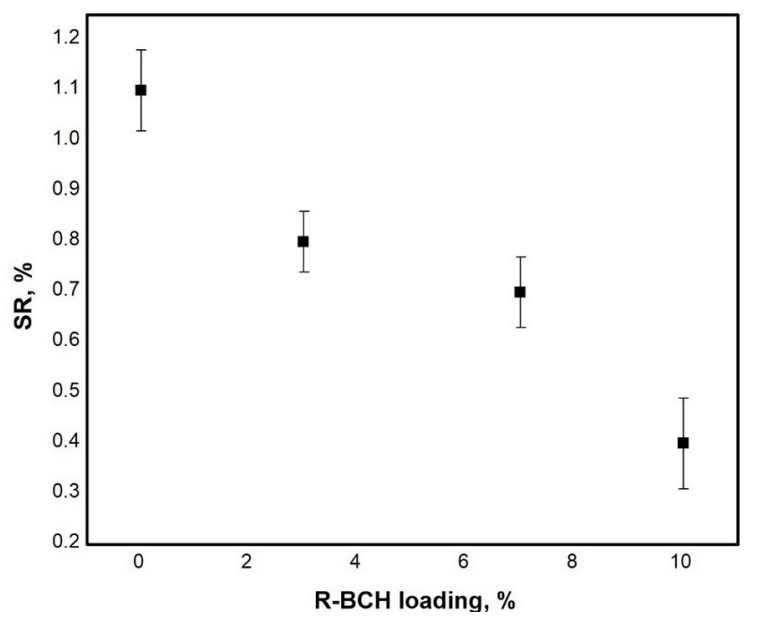

Figure 4: Effects of R-BCH loading on swelling ratio of HDPE composites.

Thermal Analysis (DSC) of HDPE Composites The DSC curves (heating and cooling processes) at $10{ }^{\circ} \mathrm{C} / \mathrm{min}$ of the HDPE and HDPE/R-BCH composites are illustrated in Figures 5 and 6 . The relative factors, for example, crystallization temperature $\left(T_{c}\right)$, melting temperature $\left(T_{m}\right)$, crystallization enthalpy $\left(\Delta \mathrm{H}_{\mathrm{c}}\right)$, and melting enthalpy $\left(\Delta \mathrm{H}_{\mathrm{m}}\right)$ for HDPE/R-BCH composites, are summarized in Table 1 . The DSC thermograms showed single peaks for the composites' heating and cooling scans (Figures 5 and 6 ). The $T_{m}$ value of pure HDPE was $135^{\circ} \mathrm{C}$, while the $T_{m}$ value of the R-BCH/HDPE composites increased with increasing the loading of R-BCH. The HDPE/10 wt. $\% \mathrm{R}-\mathrm{BCH}$ had the highest $\mathrm{T}_{\mathrm{m}}$, which was $141^{\circ} \mathrm{C}$
(Table 1). Incorporating $\mathrm{R}-\mathrm{BCH}$ in HDPE seemed to restrict the polymer chain's mobility, resulting in higher $\mathrm{T}_{\mathrm{m}}$. The addition of $\mathrm{R}-\mathrm{BCH}$ to the HDPE matrix increased the melting peak temperature. Hence the crystallinity increases progressively with loadings of the R-BCH. As a result, they displayed a higher melting peak temperature and crystallinity. The reason may be that further lower cooling rates take place with the addition of $\mathrm{R}$ $\mathrm{BCH}$, which causes longer crystallization time, thus further ideal crystals. The $\Delta H_{m}$ is an important parameter since its magnitude is directly proportional to the polymer's overall level of crystallinity $(X)$. The HDPE composite with higher $\mathrm{R}-\mathrm{BCH}$ loading also showed a higher $\Delta \mathrm{H}_{\mathrm{m}}$ value 
when compared with those with lower $\mathrm{R}-\mathrm{BCH}$ content. For the composite systems, it was observed that generally, the $\Delta \mathrm{H}_{\mathrm{m}}$ values of the composites increased with increasing $\mathrm{R}-\mathrm{BCH}$ content. The $\Delta \mathrm{H}_{\mathrm{m}}$ of pure HDPE was $179.5 \mathrm{~J} / \mathrm{g}$ and increased to $185 \mathrm{~J} / \mathrm{g}$ at the highest loading of R$\mathrm{BCH}$. The results are listed in Table 1 , which showed that the $X$ values of these composites were slightly increased relative to that of pure HDPE $(61 \%)$. Furthermore, the addition of $10 \% \mathrm{R}-\mathrm{BCH}$ in the HDPE matrix increased the $X$ value up to $66 \%$, as shown in Figure 7. Karagoz and Tuna (25) studied the impact of (various melt temperatures) on the thermal characterizations of the HDPE composite applied at different nozzle temperatures. They reported that the HDPE composite with the greatest nozzle temperature $\left(200^{\circ} \mathrm{C}\right.$ ) achieved a significant improvement in crystallinity compared to others (180 and $190^{\circ} \mathrm{C}$ ).

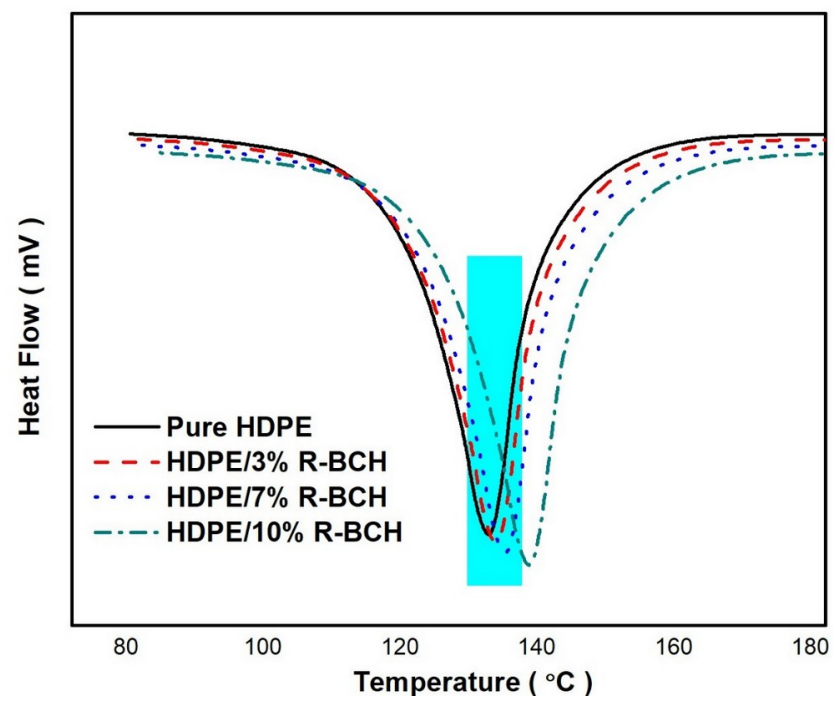

Figure 5: DSC thermograms (heating curves) of HDPE and HDPE/R-BCH composites.

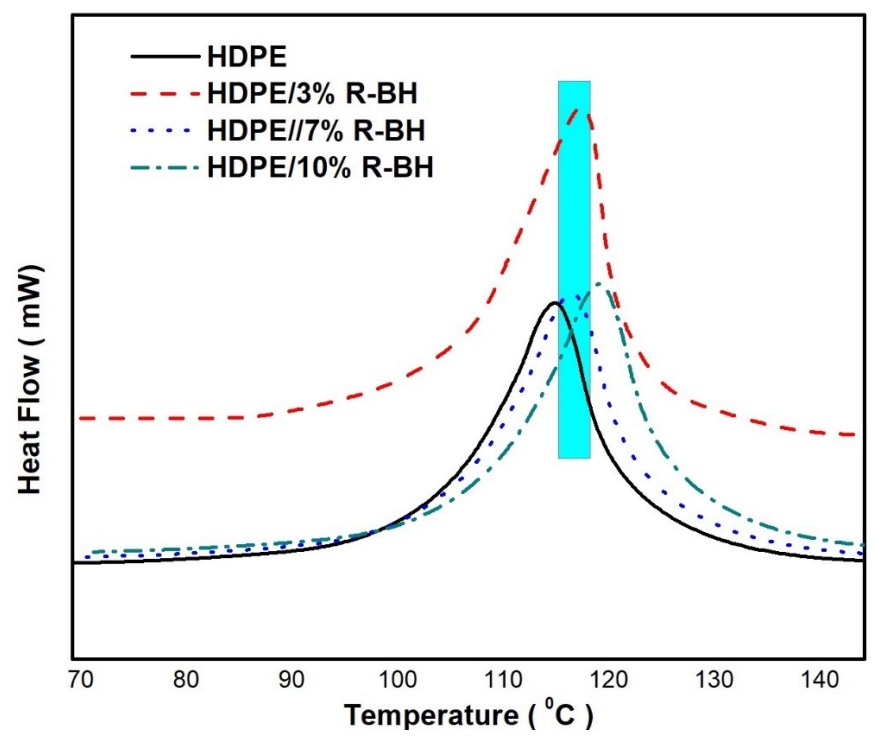

Figure 6: DSC thermograms (cooling curves) of HDPE and HDPE/R-BCH composites. 
Table 1: DSC results of non-isothermal crystallization and melting of pure HDPE and HDPE composites.

\begin{tabular}{ccccc}
\hline Composites & $\mathbf{T}_{\mathbf{c}}\left({ }^{\circ} \mathbf{C}\right)$ & $\mathbf{T}_{\mathbf{m}}\left({ }^{\circ} \mathbf{C}\right)$ & $\boldsymbol{\Delta H}_{\mathbf{c}}(\mathbf{J} / \mathbf{g})$ & $\boldsymbol{\Delta H}_{\mathbf{m}}(\mathbf{J} / \mathbf{g})$ \\
\hline Pure HDPE & 115 & 135 & 184 & 179.5 \\
HDPE/3\% R-BCH & 117 & 136 & 185 & 180.7 \\
HDPE/7\% R-BCH & 118 & 138 & 188 & 182 \\
HDPE/10\% R-BCH & 121 & 141 & 192 & 185 \\
\hline
\end{tabular}

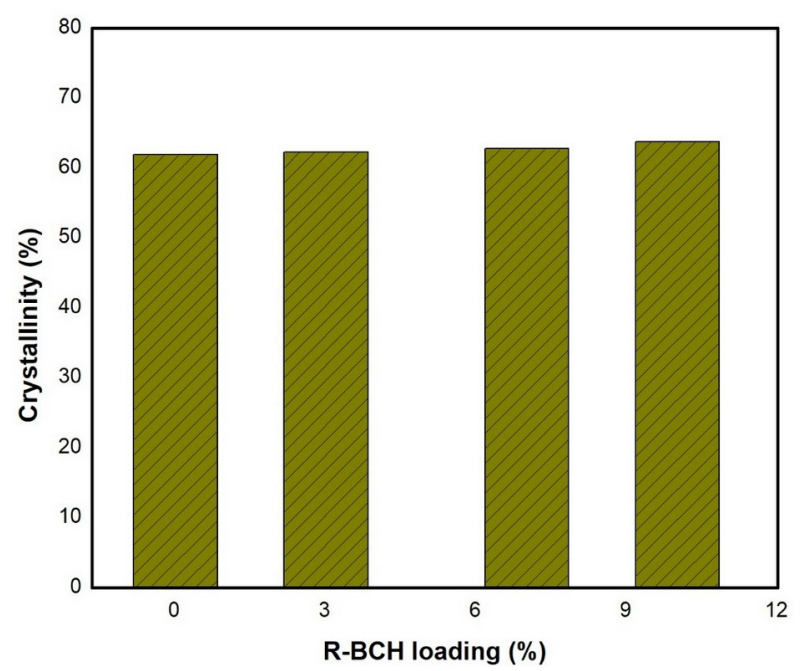

Figure 7: Crystallinity values of HDPE and HDPE/R-BCH composites.

\section{Mechanical Properties}

The results of the tensile tests are determined from tensile stress-strain curves, as shown in Figure 8. The HDPE/R-BCH composites displayed higher tensile strength and modulus when compared to the pure high-density polyethylene (HDPE). It is evident from Table 2 that tensile strength increased with increasing the loading of $\mathrm{R}-\mathrm{BCH}$ from 3 to $10 \mathrm{wt} \%$ in comparison to pure HDPE. The tensile strength of significant loading of $10 \% \mathrm{R}-\mathrm{BCH}$ was $42.5 \pm 4.8 \mathrm{MPa}$ compared with pure HDPE, which was $26 \pm 2.5 \mathrm{MPa}$. The results of Young's modulus exhibited a significant increase with $10 \% \mathrm{R}-\mathrm{BCH}$ loading, which was $296 \pm 25 \mathrm{MPa}$ by comparing to lower loadings ( 3 and $7 \% \mathrm{R}-\mathrm{BCH}$ ), and HDPE which were $(284 \pm 18 \mathrm{MPa}$ and $289 \pm 22$ $\mathrm{MPa}$ ), and $280 \pm 15 \mathrm{MPa}$, respectively, as shown in Table 2. The addition of different loadings for R$\mathrm{BCH}$ composites exhibited significant changes in the elongation at break, \%. It decreased with increasing the loading of $\mathrm{R}-\mathrm{BCH}$ in the HDPE matrix. Elongation at a break of $10 \% \mathrm{R}-\mathrm{BCH}$ in the HDPE matrix decreased to $7.4 \pm 0.6 \%$, while pure
HDPE matrix was $14.7 \pm 1.4 \%$, as shown in Table 2 . This may be attributed to the high loading of R$\mathrm{BCH}$ in the HDPE matrix, which displayed better interfacial interaction and improved the blend's plasticity by incorporating the compatibilizer (26). Previous work was studied by Idress (27), who found that the highest tensile strength for HDPE composite with a mold surface temperature of 50 ${ }^{\circ} \mathrm{C}$. By comparing with this work, Yu et al. (28) reported in their findings regarding the mechanical characterizations for particleboard dust (PB dust) and basalt fibers (BFs)/Recycled (R-HDPE), they found that the tensile strength was increased with the loading of (1BP dust:1BFs) in HDPE composite. They reported that the tensile strength of 1PB:1BFs/RHDPE composite was $28.3 \mathrm{MPa}$ while the virgin RHDPE matrix was $19.4 \mathrm{MPa}$. Poulose et al. (14) studied the properties of date palm waste extracted as biochar (BC) and utilized as biofilters for polypropylene (PP) matrix. They observed that the mechanical characterizations of BC/PP composites improved tensile strength and modulus with increased loading of BC. 


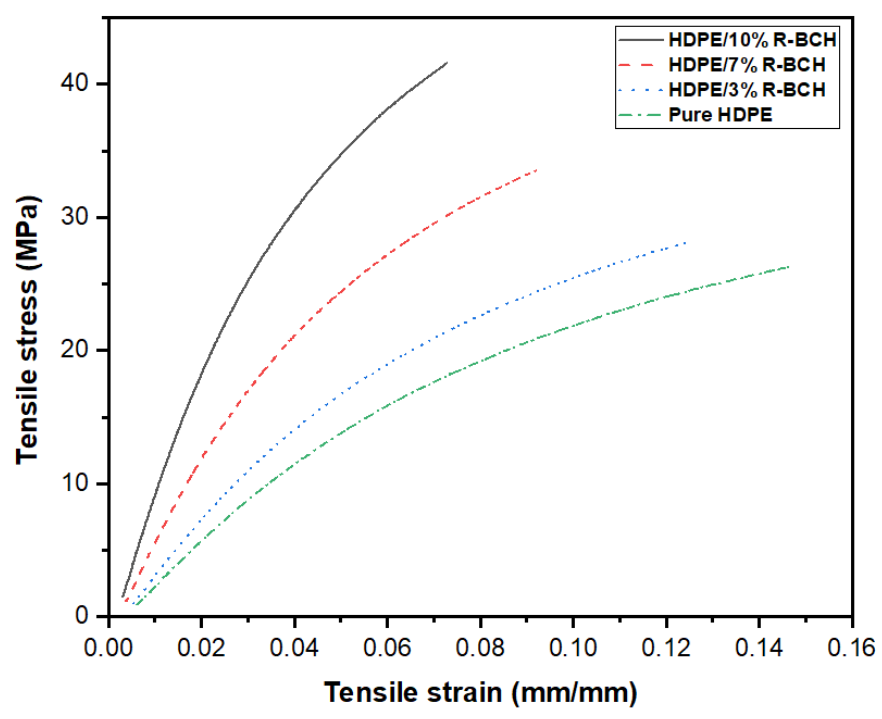

Figure 8: Tensile stress-strain curves of HDPE composites.

Table 2: Mechanical properties of pure HDPE and HDPE composites.

\begin{tabular}{cccc}
\hline Composites & $\begin{array}{c}\text { Tensile strength } \\
\text { (MPa) }\end{array}$ & $\begin{array}{c}\text { Young's } \\
\text { modulus (MPa) }\end{array}$ & $\begin{array}{c}\text { Elongation at } \\
\text { break \% }\end{array}$ \\
\hline Pure HDPE & $26.5 \pm 2.5$ & $312.5 \pm 25$ & $14.7 \pm 1.4$ \\
HDPE/3\% R-BCH & $28.2 \pm 3.5$ & $400.7 \pm 60$ & $12.5 \pm 1.1$ \\
HDPE/7\% R-BCH & $33.7 \pm 3.2$ & $650.4 \pm 50$ & $9.2 \pm 0.9$ \\
HDPE/10\% R-BCH & $42.5 \pm 4.8$ & $1020.2 \pm 75$ & $7.4 \pm 0.6$ \\
\hline
\end{tabular}

\section{CONCLUSIONS}

This study demonstrated that $\mathrm{R}-\mathrm{BCH}$ could be used as an efficient filler for the HDPE matrix. R-BCH was reinforced into HDPE by increasing the weight fractions from 3 wt. \% to 10 wt. The swelling ratio was reduced with increasing the loading of $\mathrm{R}-\mathrm{BCH}$ in the HDPE matrix. The tensile strength and modulus of R-BCH/HDPE composites were found to be improved when compared to the virgin HDPE matrix, while the elongation at break was reduced with increasing the loading of $\mathrm{R}-\mathrm{BCH}$. The thermal studies revealed that the crystallinity of $\mathrm{R}-\mathrm{BCH} / \mathrm{HDPE}$ composites was increased compared to the virgin HDPE matrix. Further investigation could be addressed towards improving the BC/PP composites characterizations by improving the biochar properties such as porosity, surface functionalization, and purity. It can be concluded that this type of bio filler $(\mathrm{R}-\mathrm{BCH})$ enhances the interaction between the HDPE matrix and $\mathrm{R}-\mathrm{BCH}$ filler and hence superior composite characterizations.

\section{CONFLICTS OF INTEREST}

The authors declared no conflict of interest.

\section{REFERENCES}

1. Awad S, Khalaf E. Evaluation of thermal and mechanical properties of Low-Density Poly Ethylene (LDPE)-Corn Flour (CF) composites. Int J Chemtech Res. 2017;10(13):230-5.

2. Awad SA, Khalaf EM. Characterisation and performance of low-density poly ethylene-corn flour composites. Aksaray University Journal of Science and Engineering. 2018;2(2):171-9. <DOI $>$.

3. Awad SA, Khalaf EM. Investigation of improvement of properties of polypropylene modified by nano silica composites. Composites Communications. 2019 Apr;12:59-63. $\leq$ DOI $>$.

4. Awad S, Khalaf E. Modified performance of mechanical, thermal, and physical properties of high-density polyethylene-corn flour composites. Usak University Journal of Engineering Sciences. 2018;1(1):38-46.

5. Trigui A, Karkri M, Peña L, Boudaya C, Candau $Y$, Bouffi $S$, et al. Thermal and mechanical properties of maize fibres-high density polyethylene biocomposites. Journal of Composite Materials. 2013 May;47(11):138797. $\leq \mathrm{DOI}>$.

6. Zhang Q, Li Y, Cai H, Lin X, Yi W, Zhang J. Properties comparison of high density polyethylene composites filled with three kinds of shell fibers. Results in Physics. 2019 Mar;12:1542-6. <DOI>. 
7. Awad S, Khalaf E. An investigation of the improvements of mechanical and thermal properties of high-density polyethene/nano clay composites. European Mechanical Science. 2019 Jun 20;3(2):41-4.

8. Awad S. Investigation of Chemical Modification and Enzymatic Degradation of Poly(vinyl alcohol)/Hemoprotein Particle Composites. Journal of the Turkish Chemical Society Section A: Chemistry. 2021 May $31 ; 8(2): 651-8$. $<$ DOI $>$.

9. Awad SA. Enhancing the Thermal and Mechanical Characteristics of Polyvinyl Alcohol (PVA)-Hemp Protein Particles (HPP) Composites. International Polymer Processing. 2021 May 26;36(2):137-43. <DOI $>$.

10. Wollerdorfer $M$, Bader $H$. Influence of natural fibres on the mechanical properties of biodegradable polymers. Industrial Crops and Products. 1998 May;8(2):105-12. $\leq$ DOI $>$.

11. Awad SA, Khalaf EM. Characterization and modifications of low-density poly ethylene-nano cellulose crystalline composites. Suranaree Journal of Science \& Technology. 2020;27(1).

12. Natalio F, Corrales TP, Feldman Y, Lew B, Graber ER. Sustainable Lightweight Biochar-Based Composites with Electromagnetic Shielding Properties. ACS Omega. 2020 Dec 22;5(50):32490-7. <DOI>.

13. Matykiewicz D. Biochar as an Effective Filler of Carbon Fiber Reinforced Bio-Epoxy Composites. Processes. 2020 Jun 22;8(6):724. <DOI>.

14. Poulose AM, Elnour AY, Anis A, Shaikh $H, A l-Z a h r a n i$ SM, George J, et al. Date palm biochar-polymer composites: An investigation of electrical, mechanical, thermal and rheological characteristics. Science of The Total Environment. 2018 Apr;619-620:311-8. <DOI>

15. Richard S, Rajadurai JS, Manikandan V. Influence of particle size and particle loading on mechanical and dielectric properties of biochar particulate-reinforced polymer nanocomposites. International Journal of Polymer Analysis and Characterization. 2016 Aug $17 ; 21(6): 462-77$. $\leq \mathrm{DOI}>$.

16. Nan N, DeVallance DB, Xie X, Wang J. The effect of bio-carbon addition on the electrical, mechanical, and thermal properties of polyvinyl alcohol/biochar composites. Journal of Composite Materials. 2016 Apr;50(9):1161-8. <DOI $>$.

17. He S, Zhou L, He H. Preparation and properties of wood plastic composites based on tea residue. Polym Compos. 2015 Dec;36(12):2265-74. <DOI>.

18. Väisänen T, Heikkinen J, Tomppo L, Lappalainen R.
Softwood Distillate as a Bio-Based Additive in WoodPlastic Composites. Journal of Wood Chemistry and Technology. 2016 Jul 3;36(4):278-87. <DOI>.

19. Das O, Sarmah AK, Bhattacharyya D. A sustainable and resilient approach through biochar addition in wood polymer composites. Science of The Total Environment. 2015 Apr;512-513:326-36. <DOI $>$.

20. Wu H, Liang $X$, Huang $L$, Xie $Y$, Tan S, Cai X. The utilization of cotton stalk bark to reinforce the mechanical and thermal properties of bio-flour plastic composites. Construction and Building Materials. 2016 Aug;118:33743. $\leq \mathrm{DOI}>$.

21. Cholake ST, Rajarao R, Henderson P, Rajagopal RR, Sahajwalla $V$. Composite panels obtained from automotive waste plastics and agricultural macadamia shell waste. Journal of Cleaner Production. 2017 May; $151: 163-71$. $\leq \mathrm{DOI}>$.

22. Awad SA, Khalaf EM. Investigation of Photodegradation Preventing of Polyvinyl Alcohol/Nanoclay Composites. J Polym Environ. 2019

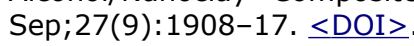

23. Awad SA, Khalaf EM. Evaluation of the photostabilizing efficiency of polyvinyl alcohol-zinc chloride composites. Journal of Thermoplastic Composite Materials. 2020 Jan;33(1):69-84. <DOI.

24. Awad SA. Mechanical and thermal characterisations of low-density polyethylene/nanoclay composites. Polymers and Polymer Composites. 2020 Oct 30;096739112096844. $\leq$ DOI $>$.

25. Karagöz İ, Tuna Ö. Effect of melt temperature on product properties of injection-molded high-density polyethylene. Polym Bull. 2021 Oct;78(10):6073-91. <DOI $>$.

26. Awad SA, Khalaf EM. Improvement of the chemical,thermal, mechanical and morphological properties of polyethylene terephthalate-graphene particle composites. Bull Mater Sci. 2018 Jun;41(3):67. $\leq \mathrm{DOI}>$.

27. Karagöz İ. An effect of mold surface temperature on final product properties in the injection molding of highdensity polyethylene materials. Polymer Bulletin. 2021;78:2627-44. $\leq$ DOI $>$.

28. Yu M, Mao $H$, Huang $R$, Ge $Z$, Tian $P$, Sun $L$, et al. Mechanical and Thermal Properties of R-High Density Polyethylene Composites Reinforced with Wheat Straw Particleboard Dust and Basalt Fiber. International Journal of Polymer Science. 2018;2018:1-10. <DOI . 